\title{
Pre-use phase LCA of a multi-story residential building: Can greenhouse gas emissions be used as a more general environmental performance indicator?
}

Jukka Heinonen ${ }^{1 *}$, Antti Säynäjoki², Juha-Matti Junnonen ${ }^{3}$, Amalia Pöyry², Seppo Junnila² $^{2}$

${ }^{1}$ University of Iceland, Faculty of Civil and Environmental Engineering, Hjardarhagi 2-6, 107 Reykjavík, Iceland

${ }^{2}$ Aalto University, Department of Real Estate, Planning and Geoinformatics, P.O. Box 15800, 00076 Aalto, Finland

${ }^{3}$ Aalto University, Department of Civil and Structural Engineering, P.O. Box 12100, 00076 Aalto, Finland

*Corresponding author: heinonen@hi.is

\section{Abstract}

Both the construction and use of buildings cause significant environmental pressures. The greenhouse gas (GHG) emissions imposed by buildings have been studied rather extensively, but less is known about other impacts. Still, climate change is only one harmful impact driven by buildings. Furthermore, no studies exist about how the other impacts are correlated with GHG emissions in the building context, and thus to what extent GHGs could be utilized as a more general environmental performance indicator. This paper fills these gaps by presenting a life cycle assessment of the pre-use phase of a modern concrete-element residential building with a very comprehensive life cycle inventory (LCl). The focus of the study is on the comparison of the accumulation of different environmental impacts relative to GHGs. The accumulation is analyzed from two perspectives common to building LCAs: building systems and different construction materials. The ReCiPe midpoint assessment method is utilized to reach wide impact category coverage. The study shows how GHGs act as a relatively good indicator for eight impact categories, but not for the others. The study also depicts that a very high coverage in the $\mathrm{LCl}$ must be reached to capture the majority of the different impacts. Many materials and building systems are considered non-relevant and are often excluded from building LCAs, which are in fact of great importance in many impact categories.

Key words: life cycle assessment, LCA, construction, ReCiPe, building, environmental impact, embodied emissions

\section{Introduction}

We are currently living unsustainably and overexploiting the planet (WWF 2014). According to Steffen et al. (2015), particularly with regard to climate change, biochemical flows, land-system change and genetic diversity we have exceeded the boundaries set by nature. Buildings and the built environment play a significant role with regard to these four areas, but also cause several other harmful impacts on the environment. 
Climate change has often been considered the most significant current threat and thus most of global attention has been on climate change mitigation and resilience to warming. Buildings alone have been assessed to cause one third of the global anthropogenic greenhouse gas (GHG) emissions, and use approximately the same share of the global energy production (UNEP 2009). Consequently, the energy requirements and the GHG impacts of buildings over their life cycles have been studied rather extensively since the late 1990s (see review papers of e.g. Sartori and Hestnes 2007 and Khasreen et al. 2009). The majority of these studies have concentrated on the whole life cycle and suggest the use phase to dominate the emissions, which has led to tightening building energy efficiency requirements around the world. More recently, however, researchers such as Blengini and di Carlo (2010), Säynäjoki et al. (2012) and Karimpour et al. (2014) have suggested more emphasis be placed on the embodied emissions in construction materials. Säynäjoki et al. (2012) especially stress the importance of the early life cycle due to its impact on the short and middle term GHG mitigation targets. It is also obvious that any improvement in the building energy efficiency increases the relative importance of the embodied emissions.

However, GHGs and climate change are but one harmful impact on both the natural and human environment driven by buildings. While climate change mitigation is currently held by many as the most important action, this might change in the future. As is evident from the review of Khasreen et al (2009), there is a significant gap in the research in the building sector looking at other categories than GHGs and energy. As GHG emissions are the only environmental impact analyzed in some of the building LCAs (or just energy requirements as a proxy) (e.g. Zabalza et al. 2009; Säynäjoki et al. 2011, Asdrubali et al. 2013), it is relevant to study if other impacts are related to GHG emissions and if GHGs can thus be utilized as an overall environmental performance indicator. If such a connection exists and the future focus shifts towards other impacts, the whole body of the existing literature and all the future studies concentrating mainly on GHGs and the impact of climate change would actually concurrently produce information about other impacts as well and potentially be of high value. Furthermore, it is likely that even if a high correlation exists between GHGs and other impacts, this connection would be limited to certain impact categories, which highlights the value of studying the issue.

Another limitation in the current body of literature is that even of the studies that have included multiple impact categories, only a very few concentrate on the early life cycle or the embodied and construction phase emissions of buildings (Thormark et al. 2000, Robertson et al. 2012, Dong and Ng 2015). The other studies have focused mainly on comparing the relative importance of the different life cycle phases (Junnila 2004, Junnila and Horvath 2003, Guggemos and Horvath 2005, Junnila et al. 2006, Kofoworola and Gheewala 2008, Passer et al. 2012). All of these, except the study of Passer et al., have also looked at office buildings, which clearly leaves a knowledge gap regarding the impacts of different building types.

There seems to be a wide consensus that life cycle assessment (LCA) provides the most comprehensive view of the environmental impacts caused by buildings and is thus the most suitable assessment method. However, there are several approaches to LCA leading to relatively different outcomes. Process LCA is the most commonly used since it is held as accurate (e.g. Bilec et al. 2006, Hendrickson et al. 2006), but it suffers from an inherent truncation error due to subjective boundary selection which may lead to underestimations of tens of percentages (e.g. Lenzen and Treloar 2006, Matthews et al. 2008). 
Furthermore, a common tradition in building LCAs is to include only the main materials or at least exclude certain systems and appliances (as done by e.g. Thormark 2000, Kofoworola and Gheewala 2008, Zabalza et al. 2009, Robertson et al. 2012). This might be justified if only certain material choices are compared, but when utilized to describe the actual impacts caused by a building, such cutoffs can be dangerous, as noted by, for example, Blengini and di Carlo (2010). Passer et al. also suggest that their comprehensive life cycle inventory $(\mathrm{LCl})$ is one of the key reasons why they report relatively high emissions among the process LCA literature. The boundary definition might thus have higher importance than considered by the authors of a certain study, since the cutoff criteria are seldom given more justification than a qualitative reasoning for the most important materials in building systems being included. Regarding impact categories other than climate change, it is even more uncertain how a certain cutoff affects the results.

In this paper we aim to narrow the gaps revealed above. To achieve this, we present an LCA study of the pre-use phase of a modern concrete-element low-energy multi-story residential building in Finland with a very comprehensive primary $\mathrm{LCl}$ including the emissions embodied in the materials, their transportation and the construction process. The focus of the study was on the comparison of the accumulation of different environmental impacts relative to GHGs when the $\mathrm{LCl}$ is extended further and further and finally including virtually all of the elements and materials used in constructing the building. This approach allows for an analysis of (1) the power of GHGs to act as an indicator for the overall environmental performance of a building and (2) the effect of cutoff criteria on different impact categories.

The accumulation of the emissions is analyzed from two perspectives common to building LCAs: building systems and different materials. We utilize the ReCiPe midpoint environmental impact assessment method (Goedkoop et al. 2013) with its 18 impact category indicators to reach wide impact category coverage. This has also been employed recently in a similar context (Dong and Ng 2014, Dong and Ng 2015) and follows the latest recommendations of the LCA community (Dahlbo et al. 2013).

The remainder of the paper is arranged in the following way: In Section 2 the case building, the assessment method and the research process are presented. In Section 3 the results are shown and itemized. Section 4 concentrates on discussion of the results and an analysis of the uncertainties related to the study.

\section{Data, method and research process}

\subsection{Pyry residential building in Härmälänranta Finland}

The case building is a modern low-energy apartment building Pyry, built by Skanska Oy and located in a brownfield development area of Härmälänranta in Tampere, Finland. Pyry is a concrete block building with a gross floor area of 3,085 $\mathrm{m} 2$ and volume of 9,645 m3, including 28 apartments with individual saunas and separate storage rooms and several common spaces. The use phase energy requirements of Pyry are estimated at $80 \mathrm{kWh} / \mathrm{m} 2 / \mathrm{a}$ of district heat and $14 \mathrm{kWh} / \mathrm{m} 2 / \mathrm{a}$ of communal building electricity (excluding household electricity), thus placing it in energy class A in Finland (Skanska 2011; Ristimäki et al. 2013). Table 1 depicts the characteristics of Pyry. A picture of the building is presented in Figure 1. 
Table 1. Characteristics of the building studied.

\begin{tabular}{lll}
\hline & Value & Unit \\
\hline Gross floor area & 3085 & $\mathrm{~m} 2$ \\
Heated area & 2821 & $\mathrm{~m} 2$ \\
Volume & 9645 & $\mathrm{~m} 3$ \\
Construction year & 2012 & year \\
Apartments & 28 & number \\
Frame & concrete & - \\
Mass & 4,400 & $\mathrm{t}$ \\
\hline
\end{tabular}

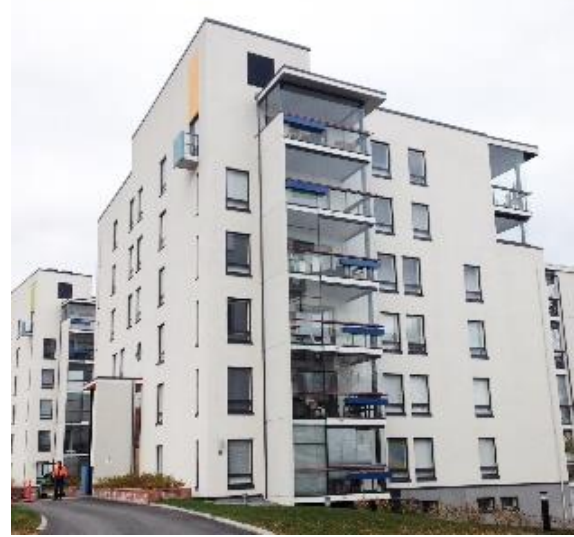

Figure 1. Pyry.

Table 2 presents the main building systems of Pyry according to the Finnish Building Classification System Talo 2000 (Building 2000) (The Building Information Foundation RTS 2010), and the main subsystems and materials of each. As to the materials overall, the M1 emission class (The Building Information Foundation 2014) requirement for the materials was set to reduce the environmental burden caused by the building. Furthermore, all the waste streams at the construction site were recycled or incinerated for energy (Skanska 2011).

Table 2. The eight main building systems of Pyry, the main entities of each and the main materials.

\begin{tabular}{|c|c|}
\hline Category & Main materials \\
\hline \multicolumn{2}{|l|}{ 1. Earth and groundwork } \\
\hline Foundation structures & reinforced concrete \\
\hline Subsurface drains and piping & polyvinyl chloride (PVC) \\
\hline \multicolumn{2}{|c|}{$\begin{array}{l}\text { 2. Foundations and external } \\
\text { structures }\end{array}$} \\
\hline Footings & reinforced concrete \\
\hline \multicolumn{2}{|c|}{ Enclosure walls and foundation } \\
\hline columns & reinforced concrete with polyurethane insulation \\
\hline Bearing ground floor & reinforced concrete with polyurethane insulation \\
\hline Disaster protection shelters & reinforced concrete \\
\hline Special structure & reinforced concrete \\
\hline External structure & gravel \\
\hline \multicolumn{2}{|l|}{ 3. Frame and roof structures } \\
\hline Bearing walls & reinforced concrete \\
\hline Hollow core slabs & reinforced concrete \\
\hline Stairs & mosaic concrete \\
\hline Concrete external walls & reinforced concrete with polyurethane and mineral wool insulation \\
\hline Wooden external walls & gypsum plasterboard, plywood, sawn timber and polystyrene \\
\hline \multicolumn{2}{|c|}{ Balconies and special external } \\
\hline decks & reinforced concrete \\
\hline Attic floor and roof & concrete, timber \\
\hline \multicolumn{2}{|l|}{ 4. Complementary works } \\
\hline Windows & triple glazed with wood-aluminum frames and insulation gas \\
\hline External doors & double glazed with aluminum frames, rock wool insulation \\
\hline
\end{tabular}


Internal doors

Lightweight partition walls

Special partition walls

Railings and ladders

Flues

\section{Finishes}

\section{Roofing}

Interior wall claddings

Ceilings

Floorings

Saunas

Painting wood

brick, ceramic tiles

steel

steel

concrete

bitumen felt, steel, polyvinyl chloride

ceramic tiles

gypsum, metal, plywood and mineral wool

cement mortar, ceramic tiles, parquet, plastic carpet

wood, polyurethane and mineral wool insulation

paint

\section{Fittings, equipment and installations}

Kitchens

Closets

Bathrooms

Accessories

\section{Mechanical works}

HVAC and electricity systems

Elevator

8. Construction site

Energy

Water

Crane foundation chipboard, steel

chipboard, steel

ceramic

steel, aluminum

plastic, copper, steel, aluminum, glass

steel

electricity, heat, fuels on-site

reinforced concrete

In addition, the materials were aggregated into eight key material categories presented in Table 3.

Table 3. The eight main material categories.

\begin{tabular}{ll}
\hline 1 & Concrete and cement products \\
2 & Steel and other metals \\
3 & Wood \\
4 & Plastic and oil products \\
5 & Glass \\
6 & Bricks and tiles \\
7 & Energy and on-site fuels \\
8 & Other \\
\hline
\end{tabular}

\subsection{Methods}

\subsubsection{Process LCA}

The study employed process LCA for assessing the pre-use stage emissions of Pyry, meaning the system boundary including the life cycle stages until the residents move in. LCA is a methodology that evaluates all environmental loads of the studied system from raw material extraction to processing, manufacturing, use and maintenance and disposal or recycling (Klöpffer, 1997; Crawford, 2011). LCA has been utilized since the '60s (e.g. Hunt \& Franklin 1996, p.4), but importantly in the building sector since the '90s (Fava 2006; Sartori and Hestnes 2007). The number of building-related LCAs has grown 
relatively quickly in the 2000s (Buyle et al. 2013). The International standard series ISO 14040:2006 (ISO 2006) is currently the main LCA standard guiding the practice.

Process LCA is the most commonly used method for LCAs and it is often considered to return the most accurate results. According to Sharrard et al. (2008) the method is especially prominent in the construction industry due to the complexity of the assessment objects. Process LCA estimates the environmental impacts over the assessment object's life cycle with a process flow diagram aiming to include all important processes into the model (Bilec et al. 2010).

Despite the believed accurateness, process LCAs inherently suffer from truncation error arising from certain upstream activities and capital requirements related to the studied system inevitably being left outside of the system boundaries (e.g. Suh et al. 2004). According to Lenzen and Treloar (2006), the truncation error can be even as high as $50 \%$. Process LCAs thus tend to systematically underestimate the emissions, although the level of the error in any certain case is very difficult to estimate. Uncertainties related to both input and output data are also general problems of the method. The impact of these shortcomings in the method is discussed in Section 4.

\subsubsection{Life Cycle Impact Assessment}

For the life cycle impact assessment (LCIA) we utilized the ReCiPe 2011 method (Goedkoop et al. 2013). ReCiPe includes 18 impact category indicators with midpoint characterization factors and normalization factors, and three endpoint categories with normalization factors measuring the harm to the selected areas of protection (Dong and $\mathrm{Ng}$ 2014). Finally, these can be merged into a single harmfulness indicator. One important feature of ReCiPe is that it includes normalization factors for both midpoint and endpoint levels which are consistent between the two levels (e.g. Dong and Ng 2014). The 18 midpoint impact category indicators also represent certain current ideas held by the LCA community on comprehensiveness in an LCA (Dahlbo et al. 2013). ReCiPe is a relatively new LCIA method, but it has been developed on the basis of CML 2001 and Ecoindicator 99 (Goedkoop et al. 2013). The utilized midpoint impact categories and the respective characterization units are presented in Table 4.

Table 4 The 18 ReCiPe impact categories and characterization units.

\begin{tabular}{ll}
\hline Impact category & Characterization unit \\
\hline Climate change & $\mathrm{kg} \mathrm{CO} 2 \mathrm{eq}$ \\
Ozone depletion & $\mathrm{kg} \mathrm{CFC}-11 \mathrm{eq}$ \\
Terrestrial acidification & $\mathrm{kg} \mathrm{SO} 2 \mathrm{eq}$ \\
Freshwater eutrophication & $\mathrm{kg} \mathrm{P}$ eq \\
Marine eutrophication & $\mathrm{kg} \mathrm{N}$ eq \\
Human toxicity & $\mathrm{kg} 1-\mathrm{DB}$ eq \\
Photochemical oxidant formation & $\mathrm{kg} \mathrm{NMVOC}$ \\
Particulate matter formation & $\mathrm{kg}$ PM10 eq \\
Terrestrial ecotoxicity & $\mathrm{kg} \mathrm{1,4-DB} \mathrm{eq}$ \\
Freshwater ecotoxicity & $\mathrm{kg} \mathrm{1,4-DB} \mathrm{eq}$ \\
Marine ecotoxicity & $\mathrm{kg} 1,4-\mathrm{DB}$ eq \\
Ionizing radiation & $\mathrm{kg} \mathrm{U235} \mathrm{eq}$ \\
Agricultural land occupation & $\mathrm{m} 2 \mathrm{a}$
\end{tabular}




$\begin{array}{ll}\text { Urban land occupation } & \mathrm{m} 2 \mathrm{a} \\ \text { Natural land transformation } & \mathrm{m} 2 \\ \text { Water depletion } & \mathrm{m} 3 \\ \text { Metal depletion } & \mathrm{kg} \mathrm{Fe} \mathrm{eq} \\ \text { Fossil depletion } & \mathrm{kg} \text { oil eq }\end{array}$

Probably the most important weakness of ReCiPe is the high variation in the level of scientific knowledge of the 18 impact categories (Dahlbo et al. 2013). With certain categories the assessment methods are significantly more advanced and the data availability on a much higher level than with some others. Furthermore, the normalization factors should be updated regularly, and they are also quite sensitive to changes in the assessment methods and knowledge about the harmfulness of a specific substance. It is also obvious, and has been noted, that interpreting and reporting the results of an LCA, especially at the midpoint level, is complex (Dong and Ng 2014). The impacts of these weaknesses are discussed in Section 4.

\subsubsection{Correlation assessment}

To estimate the correlations between climate change and other ReCiPe impact categories, we utilized Pearson's correlation equation (1). The assessed correlation thus means the relative change in the overall impact each building system or material category is causing following a concurrent change in GHGs.

$$
\operatorname{Correl}(X, Y)=\frac{\sum(x-\bar{x})(y-\bar{y})}{\sqrt{\sum(x-\bar{x})^{2}} \sum(y-\bar{y})^{2}}
$$

where $\bar{x}$ and $\bar{y}$ are the sample means.

\subsection{Research Process}

The study proceeded through the main steps of an LCA according to the ISO 14040:2006 standard (ISO 2006): goal and scope selection, boundary definition, LCl, LCIA and interpretation of the results.

1. Goal and scope selection

The goal was to conduct a comprehensive assessment of the environmental impacts of the preuse stage of Pyry and analyze the accumulation of different impacts along with GHGs. The main functional unit selected is gross square meter (referred to as $\mathrm{m} 2$ later in the paper). The impact accumulation is analyzed from two perspectives: 1 ) the main building systems presented in Table 2, and 2) the main materials listed in Table 3.

2. Boundary definition

Since we aimed at a very comprehensive assessment, outside of the assessment boundary were left mainly only the activities related to the site: site clearing, excavation and construction of the traffic area and parking area paving and site equipment. Neither were use and demolition of construction molds included. Pre-installed household appliances (kitchen and sauna stoves, freezers and dishwashers) were excluded due to the fact that their inclusion in the building is 
not the predominant international tradition. All else, including the HVAC and electricity systems, fixed furniture and the construction site activities, were taken into account.

3. $\mathrm{LCl}$

For the LCl, budgeted cost, bill of quantities, architectural and technical drawings for Pyry were obtained from the developing company Skanska Oy. The data specifies costs and volumes for approximately 600 different items. The activities at the construction site were also included in the data. The drawings were utilized to estimate the material volumes of several items, e.g. the fixed furniture. For the HVAC and electricity systems references for the material requirements were taken from Ruuska \& Häkkinen (2013) and adjusted to Pyry. In addition, most items were disaggregated further with regard to the different materials they contain. The amounts of some minor materials (e.g. paints) were estimated based on literature due to data shortages. Transport of the materials from the manufacturer to the site was assessed with an overall average of $100 \mathrm{~km}$ roundtrips with 28 ton trucks, the emissions thus allocated to different categories according to the weight distribution.

4. LCIA

Ecoinvent v.2.0 database was utilized in the assessment. The database includes over 4,000 processes (PRé Consultants 2010) and has been utilized widely in previous building LCA studies. The LCIA was conducted using the ReCiPe 2011 impact assessment method. The uncertainties brought about these choices are discussed in Section 4.

5. Interpretation of the results

The key results are presented and interpreted in Section 3. The accumulation curves from the two perspectives, building systems and main materials (see Tables 2 and 3) are presented in the order of magnitude of GHGs related to each category from largest to smallest. The correlations and the cutoff impacts are presented in tables.. The main uncertainties and limitations of the study are discussed in Section 4.

\section{Results}

\subsection{The impact categories with strong correlation with GHGs}

There are eight impact categories that have somewhat similar accumulation curves with climate change, as shown in Figure 2. With the eight impact categories of Ozone depletion, Terrestrial acidification, Marine eutrophication, Photochemical oxidant formation, Particulate matter formation, Ionizing radiation, Water depletion and Fossil depletion the GHGs would thus seem to work as a proxy, at least in our case. For these, the correlations with GHGs are $98 \%$ to $100 \%$ except for lonizing radiation, 
for

which

it

is

$94 \%$.

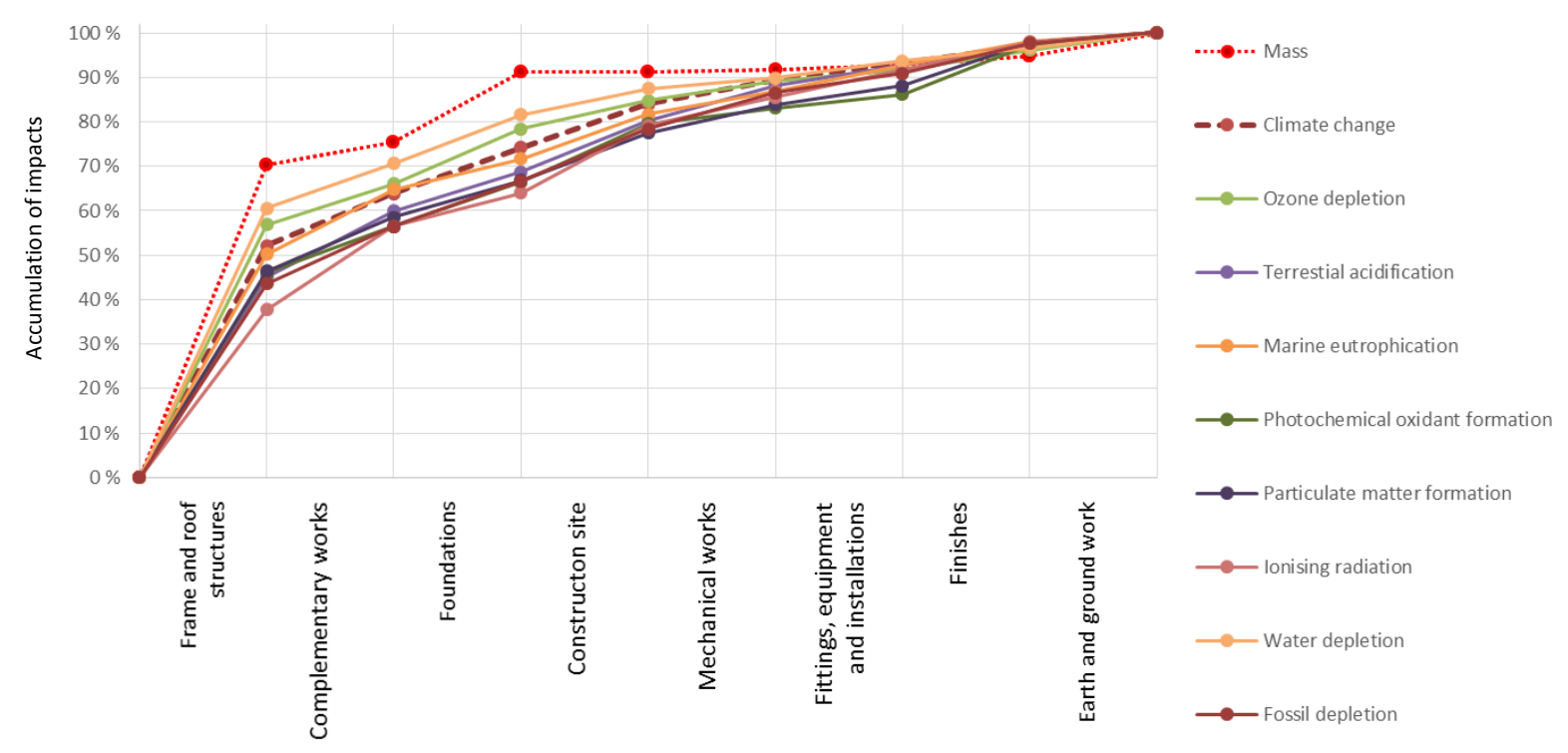

The eight building systems

Figure 2. Impact categories with strong correlation with GHGs according to the building systems.

Interestingly, the accumulation is more similar in terms of the eight building systems than in terms of the main materials, as shown by Figure 3, meaning that with the building systems the differences partly cancel out. However, with the main materials the same eight impact categories are still the most closely correlated with climate change, but the correlations fall to between $80 \%$ and $90 \%$ for Marine eutrophication, Particulate matter formation, lonizing radiation and Fossil depletion. An important issue is that the figures only indicate accumulation patterns, not the actual magnitudes or the harmfulness of the impacts. These issues will be discussed later in the paper. 


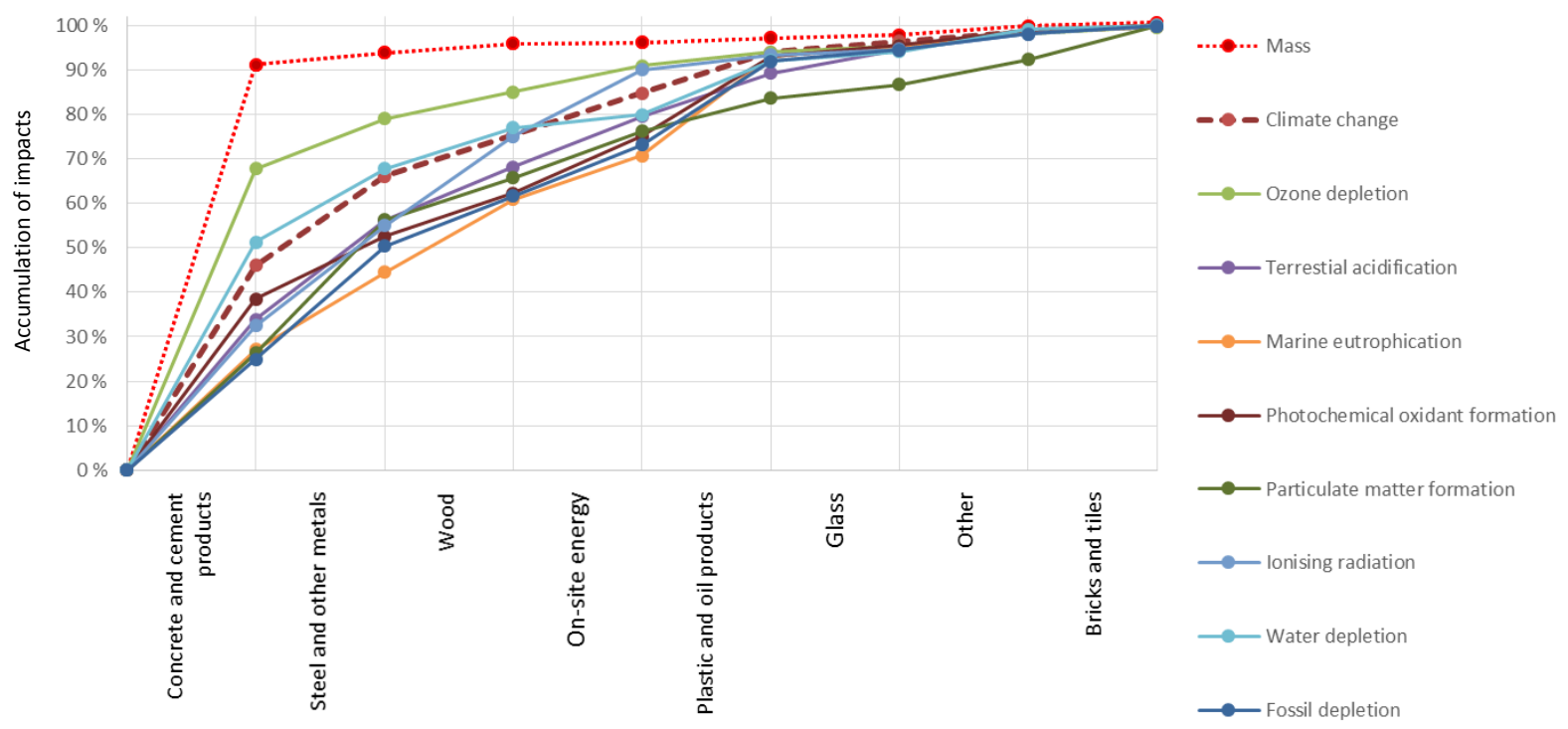

The main materials

Figure 3. Impact categories with strong correlation with GHGs according to the main materials.

\subsection{The impact categories with weak correlation with GHGs}

For nine impact categories Climate change is not such a good indicator. These impact categories are Freshwater eutrophication, Human toxicity, Terrestrial ecotoxicity, Freshwater ecotoxicity, Marine ecotoxicity, Agricultural land occupation, Urban land occupation, Natural land transformation and Metal depletion, as depicted in Figure 4. However, the correlations are still between $70 \%$ and $80 \%$ for many categories and close to zero only for Agricultural land occupation.

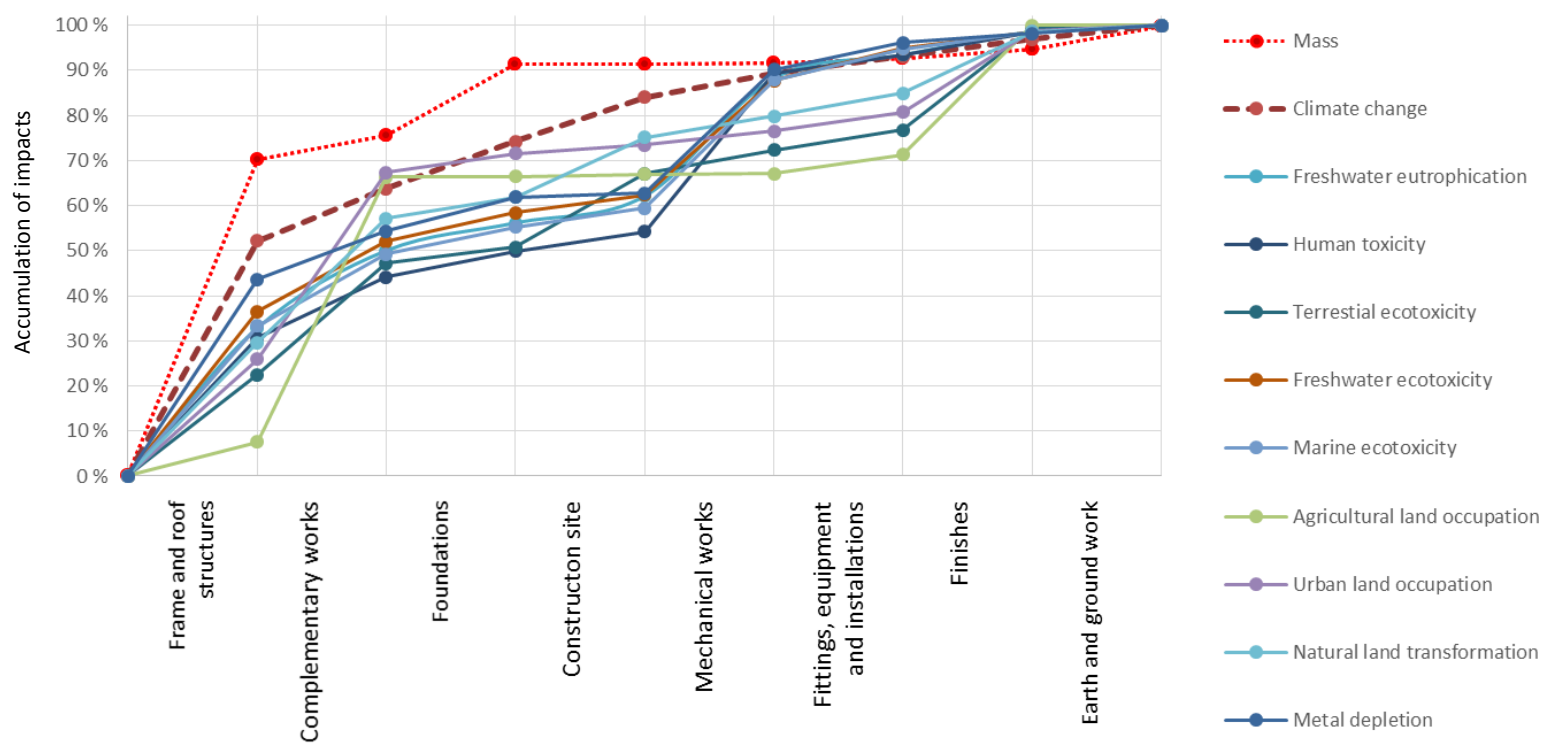


Figure 4. Impact categories with weak correlation with GHGs according to the building systems.

Again the differences within the building system categories cancel each other out to a certain extent, since with the main materials, Figure 5, the correlations for these nine impact categories fall to from zero to slightly over $30 \%$, except for Natural land transformation for which it is $47 \%$. Figures 3 and 4 depict how the accumulation curves vary randomly around Climate change.
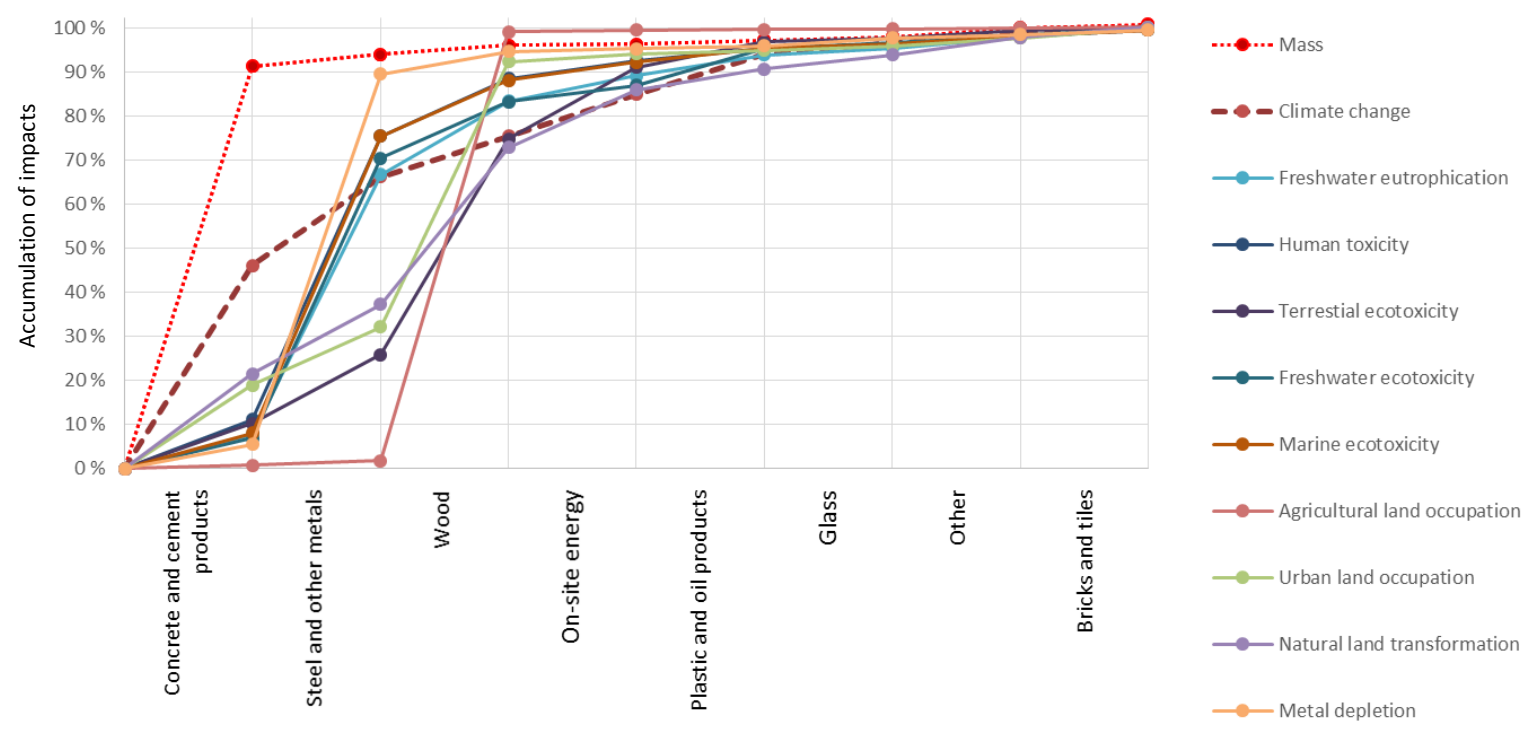

The main materials

Figure 5. Impact categories with weak correlation with GHGs according to the main materials.

\subsection{The cutoff impacts of an incomprehensive assessment}

\subsubsection{Building systems}

Despite the accumulation patterns, the cutoffs are so significant that a $95 \%$ coverage of the emissions in all the impact categories requires virtually all systems and materials to be covered in the $\mathrm{LCl}$. If $95 \%$ coverage of the emissions is targeted, as often in LCAs, from the perspective of the building systems only Earth and groundwork could be left out of the assessment, as visualized in Table 5. This is also actually due to our categorization that separate on-site energy and fuels to Construction site. From the materials perspective, all of our eight categories have over $5 \%$ share in at least one impact category leading the assessment to reach below 95\% coverage in one or more impact categories. Table 5 depicts how the $95 \%$ level is only achieved by including the first six system categories in all except three impact categories.

Table 5. Visualization of the cutoffs in different impact categories of omitting certain building system categories. 
Climate change

Marine eutrophication

Water depletion

Ozone depletion

Terrestial acidification

Photochemical oxidant formation

Particulate matter formation

Freshwater eutrophication

Urban land occupation

Natural land transformation

Freshwater ecotoxicity

Metal depletion

lonising radiation

Fossil depletion

Human toxicity

Marine ecotoxicity

Terrestial ecotoxicity

Agricultural land occupation

Mass

\begin{tabular}{|c|c|c|c|c|c|c|c|c|}
\hline 1 & 2 & 3 & 4 & 5 & 6 & 7 & 8 & \\
\hline $52 \%$ & $64 \%$ & $74 \%$ & $84 \%$ & $89 \%$ & $93 \%$ & $97 \%$ & $100 \%$ & 1 Frame and roof structures \\
\hline $50 \%$ & $65 \%$ & $72 \%$ & $82 \%$ & $87 \%$ & $93 \%$ & $98 \%$ & $100 \%$ & 2 Complementary works \\
\hline $61 \%$ & $71 \%$ & $82 \%$ & $87 \%$ & $90 \%$ & $94 \%$ & $97 \%$ & $100 \%$ & 3 Foundations \\
\hline $57 \%$ & $66 \%$ & $78 \%$ & $85 \%$ & $89 \%$ & $92 \%$ & $96 \%$ & $100 \%$ & 4 Costruction site \\
\hline $45 \%$ & $60 \%$ & $69 \%$ & $80 \%$ & $88 \%$ & $93 \%$ & $98 \%$ & $100 \%$ & 5 Mechanical works \\
\hline $46 \%$ & $56 \%$ & $66 \%$ & $80 \%$ & $83 \%$ & $86 \%$ & $97 \%$ & $100 \%$ & 6 Fittings, equipment and installations \\
\hline $46 \%$ & $58 \%$ & $67 \%$ & $77 \%$ & $84 \%$ & $88 \%$ & $98 \%$ & $100 \%$ & 7 Finishes \\
\hline $33 \%$ & $50 \%$ & $56 \%$ & $62 \%$ & $88 \%$ & $93 \%$ & $99 \%$ & $100 \%$ & 8 Earth and ground work \\
\hline $26 \%$ & $67 \%$ & $71 \%$ & $73 \%$ & $76 \%$ & $81 \%$ & $99 \%$ & $100 \%$ & \\
\hline $30 \%$ & $57 \%$ & $62 \%$ & $75 \%$ & $80 \%$ & $85 \%$ & $99 \%$ & $100 \%$ & Range \\
\hline $36 \%$ & $52 \%$ & $58 \%$ & $62 \%$ & $88 \%$ & $95 \%$ & $99 \%$ & $100 \%$ & \\
\hline $44 \%$ & $54 \%$ & $62 \%$ & $63 \%$ & $90 \%$ & $96 \%$ & $98 \%$ & $100 \%$ & $0-24$ \\
\hline $38 \%$ & $56 \%$ & $64 \%$ & $79 \%$ & $85 \%$ & $92 \%$ & $98 \%$ & $100 \%$ & $25-49$ \\
\hline $44 \%$ & $56 \%$ & $67 \%$ & $78 \%$ & $87 \%$ & $91 \%$ & $98 \%$ & $100 \%$ & $50-74$ \\
\hline $31 \%$ & $44 \%$ & $50 \%$ & $54 \%$ & $89 \%$ & $93 \%$ & $98 \%$ & $100 \%$ & $75-100$ \\
\hline $33 \%$ & $49 \%$ & $55 \%$ & $59 \%$ & $88 \%$ & $95 \%$ & $99 \%$ & $100 \%$ & $95-100$ \\
\hline $22 \%$ & $47 \%$ & $51 \%$ & $67 \%$ & $72 \%$ & $77 \%$ & $99 \%$ & $100 \%$ & \\
\hline $8 \%$ & $66 \%$ & $66 \%$ & $67 \%$ & $67 \%$ & $71 \%$ & $100 \%$ & $100 \%$ & \\
\hline
\end{tabular}

\begin{tabular}{|l|lllll|ll|}
\hline $70 \%$ & $76 \%$ & $91 \%$ & $91 \%$ & $92 \%$ & $93 \%$ & $95 \%$ & $100 \%$ \\
\hline
\end{tabular}

Drawn from Table 5, Table 6 shows the minimum and maximum contribution of each building system. If the minimum value is (close to) zero, the building system or the material category could be left out in at least one impact category without compromising the coverage. Thus, only Frame and roof structures and Complementary works should not be left out in any assessment from the perspective of the building systems. However, exactly Complementary works is a category often left out as insignificant.

The maximum values show the maximum contribution of a certain building system among the 18 impact categories of ReCiPe. These values show how large a share would be cut off in at least one impact category. Thus, for example regarding Complementary works, $59 \%$ of the overall impact would be cut off in Agricultural land occupation if Complementary works is not included in the assessment. Earth and groundwork remains thus the only building system which could be cut off without compromising the $95 \%$ coverage in any impact category.

Table 6. Minimum and maximum contributions of the eight building systems in the 18 ReCiPe impact categories.

\begin{tabular}{|c|c|c|c|c|c|c|c|c|}
\hline & 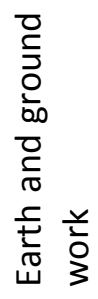 & $\frac{\mathscr{d}}{\frac{\mathscr{n}}{\mathscr{E}}}$ & 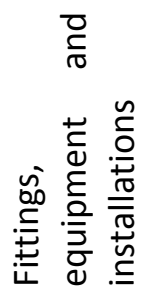 & 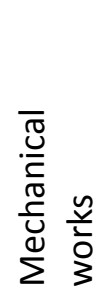 & 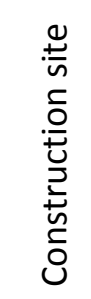 & $\begin{array}{l}\frac{n}{0} \\
.0 \\
\frac{0}{T} \\
0 \\
\frac{0}{3} \\
0 \\
4\end{array}$ & 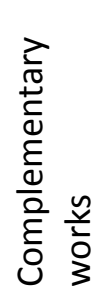 & 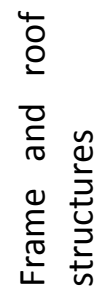 \\
\hline MAX & $4 \%$ & $29 \%$ & $7 \%$ & $35 \%$ & $16 \%$ & $12 \%$ & $59 \%$ & $61 \%$ \\
\hline MIN & $0 \%$ & $2 \%$ & $2 \%$ & $0 \%$ & $0 \%$ & $0 \%$ & $9 \%$ & $8 \%$ \\
\hline
\end{tabular}




\subsubsection{Materials}

With regard to the materials, the accumulation is slightly different, but again reaching the $95 \%$ coverage in all the 18 ReCiPe impact categories requires that virtually all the materials be included, as depicted in Table 7. The category of Bricks and tiles does not play an important role in Pyry, but all the other materials are required to reach the $95 \%$ level in all the 18 impact categories, actually even Bricks and tiles in Particulate matter formation.

Table 7. Visualization of the cutoffs in different impact categories of omitting certain material categories.

Climate change
Ozone depletion
Water depletion
Photochemical oxidant formation
Terrestial acidification
Fossil depletion
lonising radiation
Marine eutrophication
Particulate matter formation
Human toxicity
Natural land transformation
Urban land occupation
Freshwater ecotoxicity
Freshwater eutrophication
Marine ecotoxicity
Terrestial ecotoxicity
Metal depletion
Agricultural land occupation

Mass

\begin{tabular}{|c|c|c|c|c|c|c|c|c|}
\hline 1 & 2 & 3 & 4 & 5 & 6 & 7 & 8 & \\
\hline $46 \%$ & $66 \%$ & $76 \%$ & $85 \%$ & $94 \%$ & $96 \%$ & $99 \%$ & $100 \%$ & 1 Concrete and cement products \\
\hline $68 \%$ & $79 \%$ & $85 \%$ & $88 \%$ & $94 \%$ & $96 \%$ & $99 \%$ & $100 \%$ & 2 Steel and other metals \\
\hline $51 \%$ & $68 \%$ & $71 \%$ & $83 \%$ & $92 \%$ & $94 \%$ & $99 \%$ & $100 \%$ & 3 Energy and on-site fuels \\
\hline $39 \%$ & $53 \%$ & $65 \%$ & $83 \%$ & $93 \%$ & $96 \%$ & $99 \%$ & $100 \%$ & 4 Plastic and oil products \\
\hline $34 \%$ & $56 \%$ & $68 \%$ & $77 \%$ & $89 \%$ & $95 \%$ & $99 \%$ & $100 \%$ & 5 Wood \\
\hline $25 \%$ & $50 \%$ & $62 \%$ & $81 \%$ & $92 \%$ & $95 \%$ & $98 \%$ & $100 \%$ & 6 Glass \\
\hline $32 \%$ & $55 \%$ & $70 \%$ & $73 \%$ & $93 \%$ & $95 \%$ & $98 \%$ & $100 \%$ & 7 Other \\
\hline $27 \%$ & $44 \%$ & $54 \%$ & $77 \%$ & $93 \%$ & $96 \%$ & $99 \%$ & $100 \%$ & 8 Bricks and tiles \\
\hline $26 \%$ & $56 \%$ & $67 \%$ & $74 \%$ & $84 \%$ & $87 \%$ & $92 \%$ & $100 \%$ & \\
\hline $11 \%$ & $76 \%$ & $80 \%$ & $83 \%$ & $96 \%$ & $97 \%$ & $99 \%$ & $100 \%$ & Range \\
\hline
\end{tabular}

\begin{tabular}{l|r|rr|rrr|r}
$22 \%$ & $37 \%$ & $50 \%$ & $55 \%$ & $91 \%$ & $94 \%$ & $98 \%$ & $100 \%$
\end{tabular}

\begin{tabular}{l|lll|lllll}
$19 \%$ & $32 \%$ & $34 \%$ & $35 \%$ & $95 \%$ & $96 \%$ & $98 \%$ & $100 \%$
\end{tabular}

\begin{tabular}{l|ll|l|l|l|l|l|l|}
7 & $71 \%$ & $74 \%$ & $83 \%$ & $96 \%$ & $97 \%$ & $99 \%$ & $100 \%$ \\
\hline
\end{tabular}

\begin{tabular}{l|ll|lll|lll}
$8 \%$ & $67 \%$ & $73 \%$ & $78 \%$ & $94 \%$ & $96 \%$ & $98 \%$ & $100 \%$
\end{tabular}

\begin{tabular}{l|lll|lllll}
\hline $8 \%$ & $76 \%$ & $80 \%$ & $83 \%$ & $96 \%$ & $97 \%$ & $99 \%$ & $100 \%$ \\
\hline
\end{tabular}

\begin{tabular}{l|lllllll|}
\hline $10 \%$ & $26 \%$ & $42 \%$ & $48 \%$ & $97 \%$ & $98 \%$ & $99 \%$ & $100 \%$
\end{tabular}

\begin{tabular}{|l|lll|llll|}
\hline $5 \%$ & $90 \%$ & $91 \%$ & $91 \%$ & $96 \%$ & $98 \%$ & $99 \%$ & $100 \%$
\end{tabular}

\begin{tabular}{llll|llllll}
$1 \%$ & $2 \%$ & $2 \%$ & $2 \%$ & $99 \%$ & $100 \%$ & $100 \%$ & $100 \%$ \\
\hline
\end{tabular}

\begin{tabular}{|lll|llllll|}
\hline $91 \%$ & $93 \%$ & $94 \%$ & $95 \%$ & $97 \%$ & $97 \%$ & $99 \%$ & $100 \%$ \\
\hline
\end{tabular}

Table 8 shows again the minimums and maximums, depicting how only wood has the minimum value of at least 5\%, its omission thus compromising the 95\% coverage in all the 18 impact categories. However, again, precisely this category might easily be incomplete due, for example, excluding fixed furniture from the assessment. Wood also forms $97 \%$ of the impact on Agricultural land occupation and half of the impact on Terrestrial ecotoxicity. On the other hand, only Glass has the maximum value of $5 \%$ or below and could thus be left out without compromising a 95\% coverage target in any impact category. For example, Plastic and oil products reach shares of over $10 \%$ in several impact categories and $9 \%$ even in Climate change, despite belonging to categories often suffering from cutoffs.

Table 8. Minimum and maximum contributions of the eight main materials in the 18 ReCiPe impact categories. 


\begin{tabular}{|c|c|c|c|c|c|c|c|c|}
\hline & 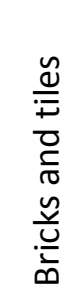 & 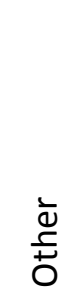 & $\begin{array}{l}\tilde{n} \\
\frac{\tilde{\sigma}}{v}\end{array}$ & 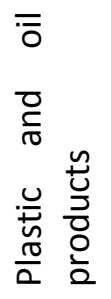 & 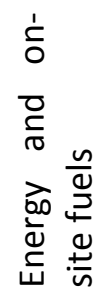 & $\begin{array}{l}0 \\
8 \\
3 \\
3\end{array}$ & 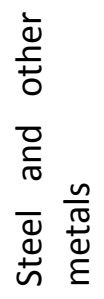 & 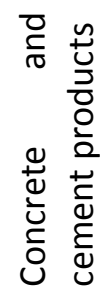 \\
\hline MAX & $8 \%$ & $6 \%$ & $5 \%$ & $22 \%$ & $16 \%$ & $97 \%$ & $84 \%$ & $68 \%$ \\
\hline MIN & $0 \%$ & $0 \%$ & $0 \%$ & $0 \%$ & $0 \%$ & $5 \%$ & $1 \%$ & $1 \%$ \\
\hline
\end{tabular}

Figures 2-5 and Tables 5 and 7 show also the mass accumulation. They clearly depict that mass is not a good proxy for virtually any impact category and should thus not be utilized as a cutoff criterion From the materials perspective, 95\% mass level means roughly concrete and cement products and metals, traditionally included in all building LCAs, and wood. However, in only three impact categories together they capture over $90 \%$ of the overall emissions: Agricultural land occupation (99\%), Metal depletion (95\%) and Urban land occupation (92\%). On the other hand, in several categories they only account for 50 to $60 \%$ of the emissions. Regarding the building systems (Figures 1 and 2), 95\% of the mass is reached with the first four systems. They comprise only 50 to $85 \%$ of the emissions in all the impact categories. Thus, including categories with insignificant masses is important in emissions.

Furthermore, no single building component, system or main material provides sufficient information about the overall emissions in any impact category. While Frame and roof structures is the single most important system in the majority of the impact categories (Figures 2 and 4), it only accounts for from below $10 \%$ to approximately $60 \%$ of the overall emissions in each category. Thus, even in a concrete element building like Pyry, other materials have significant overall impact in virtually all impact categories.

\section{Discussion and Conclusions}

The aim of this study was twofold: (1) to study the correlation between GHGs and other environmental impact categories in the pre-use phase of an apartment building, and (2) to analyze the cutoff impacts of an incomplete assessment from the perspectives of leaving out certain building systems or materials. As identified in the Introduction, there is a gap in the previous literature regarding the impacts of different commonly utilized cutoff criteria, whereas any building LCA seldom covers $100 \%$ of the construction materials and activities. Furthermore, since GHGs and climate change have been the nexus of research for some time, less is known about the other emission categories. As we also seem to be exceeding the carrying capacity of our planet in categories other than climate change (Rockström et al. 2009; WWF 2014; Steffen et al. 2015), new information about them is needed.

We employed process LCA with a highly detailed LCI to assess the overall emissions of a 3085 gross $\mathrm{m}^{2}$ low-energy concrete-block apartment building in Tampere, Finland, utilizing the 18 midpoint impact category indicators of ReCiPe method. The accumulation of the emissions was studied from two key perspectives: (1) different building systems (utilizing the Finnish Building Classification System Talo 2000 (Building 2000) (The Building Information Foundation RTS 2010), and (2) main material groups. 
We made several interesting and important findings. First, in our case, GHGs could act as a relatively good indicator for eight of 17 other impact categories, with which the correlation coefficients were well above $90 \%$ when the building systems were looked at. Interestingly, the building systems seem to comprise different materials so that the differences in the impacts partially cancel each other out and the correlations are significantly higher than with materials based assessment. However, the same impact categories remained as the best explained by GHGs when the materials were analyzed, even though the correlations fell, although still remaining above $80 \%$ for all. A considerable gap from these eight impact categories to the remaining nine was found as well. Thus, overall any streamlined onecategory LCA such as GHG assessment can be utilized as a more general indicator of environmental impacts, though only limitedly and only if the magnitudes are well understood instead of just the accumulation patterns, which was the focus in this study. This finding is also in line with the results of, for example, Laurent et al. (2012) who studied the limitations of GHGs as an indicator of wider environmental sustainability in general.

Secondly, our assessment and analysis depicts that such materials and building systems that are often excluded from building LCAs account for significant shares of the emissions in many of the included impact categories. All concrete and metal products together account for less than $40 \%$ in many impact categories. Wood accounts for $5 \%$ to $97 \%$ in all the 18 ReCiPe categories. Mechanical works, finishes and Construction site activities add 15 to 35\% in several categories, but are often excluded from building LCAs. Plastic and oil products are very important in several categories while having negligible impact in some others in our case.

To understand the relative magnitudes of the ascertained quantities in the 18 ReCiPe categories, midpoint normalization to the European average per capita from SimaPro/Ecoinvent was utilized. Midpoint normalization was selected instead of the endpoints since fewer assumptions and value choices are required (Bare et al. 2006). The normalized results of the construction project are presented in Table 9, which shows that Climate change is in the bottom half in relative importance despite being the most commonly assessed category.

Table 9 Normalized results.

\begin{tabular}{lr}
\hline Impact category & Normalized result \\
\hline Climate change & 112 \\
Ozone depletion & 9 \\
Terrestrial acidification & 128 \\
Freshwater eutrophication & 806 \\
Marine eutrophication & 29 \\
Human toxicity & 782 \\
Photochemical oxidant formation & 109 \\
Particulate matter formation & 157 \\
Terrestrial ecotoxicity & 28 \\
Freshwater ecotoxicity & 791 \\
Marine ecotoxicity & 1028 \\
lonizing radiation & 34 \\
Agricultural land occupation & 165
\end{tabular}


Urban land occupation

Natural land transformation

Water depletion

Metal depletion

Fossil depletion
1526

0

326

199

The highest impacts according to this normalization method are found in Natural land transformation, Marine ecotoxicity, Freshwater eutrophication, Freshwater ecotoxicity and Human toxicity. On the other hand, Water depletion, Ozone depletion, lonizing radiation and Urban land occupation show as merely negligible. However, one must bear in mind that these are the results of this particular normalization method and based on our current knowledge, and thus it would be careless to say that the normalized results are fully reliable. When normalizing the results, the point of comparison is significant and might cause biased interpretations. Furthermore, especially the assessments of the toxic impact categories include severe uncertainties, as there are thousands of substances causing toxic impacts with no wellproven systems of monitoring and reporting (Laurent et al. 2011). On the other hand, the results for the conventional impact categories (Climate change, Terrestrial acidification, Freshwater eutrophication, Photochemical oxidant formation, Particulate matter formation, Metal depletion and Fossil depletion) are generally relatively reliable due to considerable experience of reporting inventories on national and European levels as well as established characterization models (Dahlbo et al. 2013). Of those, Freshwater eutrophication scores the highest and thus can be considered to account for a relatively significant impact.

We also looked at the emissions accumulation relative to masses from the perspective of the main materials having the highest masses. Even now the conclusion is that mass is not a good cutoff criterion, and along with the emergence of low-carbon concrete brands the mass-environmental impact connection will significantly weaken. According to Imbabi et al. (2012), for example, green cement options already exist which are able to reduce the GHGs by up to $95 \%$. Furthermore, qualities which absorb more than production-cause GHGs, thus "negative impact" cement qualities, are being developed and can be expected to reach the market in the near future. Imbabi et al. (2012) do not include other impact categories, but likely they will follow the same development.

One main uncertainty in the study is related to the preciseness of the results. Even though process LCA is in general considered as accurate and well suitable for case studies, the environmental impacts are predominantly actually assessed based on average or even case values, in our case with the ecoinvent database. Thus, while we can claim having a very precise and comprehensive data inventory, the LCIA results are subject to uncertainty since the ecoinvent data might not be very compatible with our case in certain respects. As an example, Skanska required that the materials fulfill the M1 emission class (The Building Information Foundation 2014) requirement, but the potential effect of this on the environmental impacts don't show at all in our study due to using the ecoinvent data. This is issue is discussed by Zabalza et al. (2011), who strongly suggest extending, adjusting and harmonizing the current inventory databases to take differences in construction in different countries into consideration.

Partially related to this problem, Ruuska and Häkkinen (2014) analyzed in a recent study the possible variations in the GHGs from building materials while holding all other features constant, , though the 
production methods, materials, site conditions and locations varied. Even if groundwork and substructures are not accounted for in their work (apparently having high potential variation such as floor slabs and bearing walls, the variations suggested by them are of a two- to three-fold magnitude. It is likely that other impact categories also carry such significant potential for variation, though not necessarily following the changes in GHGs. This brings about uncertainty, which is difficult to quantify or solve, but the same problem exists regarding most LCAs.

The emissions are also strongly affected by a general shortcoming of process LCA, namely truncation error (e.g. Matthews et al. 2008). The included supply chains are rarely complete and certain emissions are thus left outside the system boundary. Neither are the capital goods, such as production facilities, predominantly taken into account. In addition, assessing the emissions based on the masses of different materials (due to the final products being nonexistent in the database) leads to an underestimation of the production-related emissions in many cases. For example, with the electrical system the main materials are copper and plastic, and we have estimated the masses of these materials, but the actual final production phase is cut off, since nowhere do the emissions related to producing the actual wires and plugs actually appear. Another example of the problem is windows. The problem does not apply to all the materials, but for those it applies to, it is actually very similar to truncation error, though it cuts of the first tier whereas truncation error concerns the upper tiers. This causes an additional downward bias to the results of this study (or any similar study) due to the missing production phase impacts of many products.

The software selection also brings about some additional uncertainties. In a recent study Herrmann and Moltesen (2015) compared the results of an LCA with the two perhaps most widely utilized software programs, SimaPro and $\mathrm{GaBi}$, with a random sample of 100 unit processes. They found that although most of the results are practically identical, some differences, in particular for impact assessment, are so large that they could influence the conclusions drawn from the LCA. These differences come primarily from differences or errors in the databases of the two LCA software programs, which makes them very challenging to find for ordinary or even skilled LCA software users. The LCA of this study was conducted with SimaPro only so there are some uncertainties related to the software-related results of the study.

Another kind of limitation in our study is the single case setting. Basically the single case setting sets limitations to the interpretation of the results. We assume that a similar situation exists, at least among concrete-element residential buildings in general, but actually our study de facto only shows that such patterns in the accumulation of the different impacts are possible. The single case approach was selected due to the very high workload of conducting a process LCA of a building at the level of comprehensiveness carried out in this study, which is one of the key deficiencies of process LCAs. Regarding the case building of the study, Pyry, it represents relatively well the standard apartment building in Finland. The only exception is the insulation material in external walls. The standard insulation material is mineral wool instead of polyurethane insulation.

To conclude, we have shown in this study how GHGs could be limitedly utilized as a more general environmental impact indicator. However, more such comparisons are needed to make the conclusion robust due to the single case study nature of our study. We also depicted how virtually all the materials 
and building systems are important in at least one impact category, cutoff impacts thus being significant in assessments that are not comprehensive.

\section{Acknowledgments}

We thank Skanska Oy, the Academy of Finland (Grant 286747) and the Innovative City ${ }^{\circledR}$ Partnership Programme for enabling the study.

\section{References}

AFNOR Normalisation (2012): CEN/TC 350 Sustainability of construction works, available at: http://portailgroupe.afnor.fr/public_espacenormalisation/CENTC350/index.html, accessed 4.1.2015.

Asdrubali, F.; Baldassarri, C.; Fthenakis, V. (2013): Life cycle analysis in the construction sector: Guiding the optimization of conventional Italian buildings, Energy and Buildings, 64, 73-89.

Asif, M.; Muneer, T.; Kelley, R. (2007): Life cycle assessment: A case study of a dwelling home in Scotland, Building and Environment, 42 (3), 1391-1394.

Bare, J.C.; Gloria, T.P. (2006): Critical analysis of the mathematical relationships and comprehensiveness of life cycle impact assessment approaches, Environmental Science \& Technology, 40 (4), 1104-1113.

Bilec, M. M; Ries, R., Matthews, H. S.; Sharrard, A. L. (2006): Example of a hybrid life-cycle assessment of construction processes, Journal of Infrastructure Systems, 12, 207-15.

Bilec, M. M. (2007): A Hybrid Life Cycle Assessment Model for Construction Processes, University of Pittsburgh.

Bilec, M. M.; Ries, R.J. \& Matthews, H. S. (2010). Life-Cycle Assessment Modelling of Construction Processes, Journal of Infrastructure Systems, 16 (3), 199-205

Blengini, G. A.; Di Carlo, T. (2010): Energy-saving policies and low-energy residential buildings: An LCA case study to support decision makers in Piedmont (Italy), International Journal of Life Cycle Assessment, $15,652-665$.

Buyle, M., Braet, J. \& Audenaert, A. (2013): Life cycle assessment in the construction sector: A review, Renewable and Sustainable Energy Reviews, 26, 379-388.

Börjesson, P.; Gustavsson, L. (2000): Greenhouse gas balances in building construction: Wood versus concrete from life-cycle and forest land-use perspectives, Energy Policy, 28, 575-588.

Carnegie Mellon University Green Design Institute (2008): Economic Input-Output Life Cycle Assessment (EIO-LCA) US 2002 Industry Benchmark Model, available at: www.eiolca.net, accessed 4.1.2015.

Chang, Y., Ries, R. J. \& Wang, Y. (2011): The quantification of the embodied impacts of construction projects on energy, environment, and society based on I-O LCA, Energy Policy, 39 (10), 6321-6330

Crawford R. H. (2011): Life Cycle Assessment in the Built Environment, London: Spon Press. 
Curran, M.A.; Mann, M.; Norris, G. (2001): Report on the International Workshop on Electricity Data for Life Cycle Inventories, US Environmental Protection Agency, Cincinnati, USA.

Dahlbo, H.; Koskela, S.; Pihkola, H.; Nors, M.; Deferley, M.; Seppälä, J. (2013): Comparison of different normalised LCIA results and their feasibility in communication, International Journal of Life Cycle Assessment, 18, 850-860.

Dong, Y.; Ng, S. (2014): Comparing the midpoint and endpoint approaches based on ReCiPe - A study of commercial buildings in Hong Kong, International Journal of Life Cycle Assessment, 19, 1409-1423.

Dong, Y. H.; Ng, S. T. (2015): A life cycle assessment model for evaluating the environmental impacts of building construction in Hong Kong, Building and Environment, 89, 183-191.

Fava, J. (2006): Will the Next 10 Years Be as Productive in Advancing Life Cycle Approaches as the Last 15 Years? International Journal of Life Cycle Assessment, 11, 6-8.

Goedkoop, M.; Heijungs, R.; Huijbregts, M.; De Schryver, A.; Struijs, J.; van Zelm, R. (2013): ReCiPe 2008: A life cycle impact assessment method which comprises harmonised category indicators at the midpoint and the endpoint level, Ministerie van VROM, The Hague, The Netherlands.

Guggemos, A. A. \& Horvath, A. (2005): Comparison of Environmental Effects of Steel- and ConcreteFramed Buildings. Journal of Infrastructure Systems, 11 (2), 93-101.

Hendrickson, C. T.; Lave, L. B.; Matthews, H. S. (2006): Environmental Life Cycle Assessment of Goods and Services: An Input-Output Approach, Resources for the Future Press.

Herrmann, I.; Moltesen, A. (2015): Does it matter which life cycle assessment (LCA) tool you choose? A comparative assessment of SimaPro and GaBi, Journal of Cleaner Production, 86, 163-169.

Hunt, R. G. \& Franklin, W. E. (1996): LCA History LCA - How it Came About - Personal Reflections on the Origin and the Development of LCA in the USA , International Journal of Life Cycle Assessment, 1 (1), 4-7.

Imbabi, M.; Carrigan, C.; McKenna, S. (2012): Trends and developments in green cement and concrete technology, International Journal of Sustainable Built Environment, 1, 194-216.

ISO 14040 Environmental Management Life Cycle Assessment Principles and Framework, International Standards Organization, Brussels, Belgium, 2006.

Junnila, S. (2004): Life cycle assessment of environmentally significant aspects of an office building, Nordic Journal of Surveying and Real Estate Research, Special Series, Vol. 2.

Junnila, S.; Horvath, A. (2003): Life-Cycle Environmental Effects of an Office Building, Journal of Infrastructure Systems, 9 (4), 157-166.

Junnila, S.; Horvath, A.; Guggemos, A. A. (2006): Life-cycle assessment of office buildings in Europe and the United States, Journal of Infrastructure Systems, 12 (1), 10-17.

Karimpour, M.; Belusko, M.; Xing, K.; Bruno, F. (2014): Minimising the life cycle energy of buildings: Review and analysis, Building and Environment, 73, 106-114. 
Khasreen, M.; Banfill, P.; Menzies, G. (2009): Life-Cycle Assessment and the Environmental Impact of Buildings: A Review, Sustainability, 1, 674-701.

Klöpffer, W. (1997): Life Cycle Assessment. From the Beginning to the Current State, International Journal of Life Cycle Assessment, 4(4), 223-228.

Kofoworola, O.; Gheewala, S. (2008): Environmental life cycle assessment of a commercial office building in Thailand, International Journal of Life Cycle Assessment, 13, 498-511.

Laurent, A.; Olsen, S.I.; Hauschild, M.Z. (2011): Normalization in EDIP97 and EDIP2003: Updated European inventory for 2004 and guidance towards a consistent use in practice, International Journal of Life Cycle Assessment, 16, 401-409.

Laurent, A.; Olsen, S.; Hauschild, M. (2012): Limitations of Carbon Footprint as Indicator of Environmental Sustainability, Environmental Science and Technology, 46, 4100-4108.

Lenzen, M. (2000): Errors in Conventional and Input-Output-based Life-Cycle Inventories, Journal of Industrial Ecology, 4 (4), 127-148.

Lenzen, M.; Treloar, G. (2002): Embodied energy in buildings: wood versus concrete-reply to Börjesson and Gustavsson, Energy Policy, 30, 249-255.

Leontief, W. (1970): Environmental Repercussions and the Economic Structure: An Input-Output Approach, The Review of Economics and Statistics, 52 (3), 262-271.

Matthews, S.; Hendrickson, C.; Weber, C. (2008): The Importance of Carbon Footprint Estimation Boundaries, Environmental Science and Technology, 42, 5839-5842.

Pasanen, P., Korteniemi, J. \& Sipari, A. (2011): Carbon footprint study for a passive house type woodenframed apartment building (Passiivitason asuinkerrostalon elinkaaren hiilijalanjälki). Sitran Selvityksiä, Helsinki, Finland. (In Finnish)

Passer, A.; Kreiner, H.; Maydl, P. (2012): Assessment of the environmental performance of buildings: A critical evaluation of the influence of technical building equipment on residential buildings, International Journal of Life Cycle Assessment, 17, 1116-1130.

PRé Consultants (2010): Introduction into LCA with SimaPro 7, available at: http://www.presustainability.com/download/manuals/SimaPro7IntroductionToLCA.pdf, accessed 4.1.2015.

Ristimäki, M., Säynäjoki, A., Heinonen, J., Junnila, S. (2013): Combining life cycle costing and life cycle assessment for an analysis of a new residential district energy system design, Energy, 63, 168-179.

Robertson, A.; Lam, F.; Cole, R. (2012): Comparative Cradle-to-Gate Life Cycle Assessment of Mid-Rise Office Building Construction Alternatives: Laminated Timber or Reinforced Concrete, Buildings, 2, 245270.

Rockström, J.; Steffen, W.; Noone, K.; Persson, Å.; Chapin, S.; Lambin, E.; et al. (2009): A safe operating space for humanity, Nature, 461 (24), 472-475. 
Ruuska A.; Häkkinen T. (2013): Rakennusmateriaalien ympäristövaikutukset - Taustaraportti, 97 pp, VTT, Finland (in Finnish).

Saari, A. (2001): Environmental Information of Buildings and Building Components, Helsinki: Buildings Information Foundation RTS (Rakennusten ja rakennusosien ympäristöselosteet, Rakennustietosäätiö RTS). (In Finnish)

Sartori, I.; Hestnes, A. (2007): Energy use in the life cycle of conventional and low-energy buildings: A review article, Energy and Buildings, 39, 249-257.

Sharma, A.; Saxena, A.; Sethi, M.; Shree, V. (2011): Life cycle assessment of buildings: A review, Renewable and Sustainable Energy Reviews, 15 (1), 871-875.

Sharrard, A. L.; Matthews, S. H.; Ries, R. J. (2008): Estimating Construction Project Environmental Effects Using an Input-Output-Based Hybrid Life-Cycle Assessment Model, Journal of Infrastructure Systems, 14 (4), 327-336.

Skanska, (2011): Hyvän olon järvenrantakoti Härmälänrannan Pyry, Viima ja Tuisku Tampere, available at: http://skanska.smartpage.fi/fi/esitteet/pyry-viima-tuisku/files/Skanska_Pyry_Viima_Tuisku.pdf, accessed 4.1.2015. (In Finnish)

Skanska (2012): Härmälänranta, Finland, available at: http://skanska-sustainability-casestudies.com/Case-Studies/harmalanranta-finland/project-introduction, accessed 4.1.2015. (In Finnish)

Statistics Finland (2015): Structural business and financial statement statistics [e-publication]. ISSN=2342-6233. Helsinki: Statistics Finland [referred: 17.2.2015]. Available: http://www.stat.fi/til/yrti/tau_en.html.

Steffen, W.; Richardson, K.; Rockström, J.; Cornell, S.; Fetzer, I.; Bennett, E.; Biggs, R.; Carpenter, S.; de Vries, W.; de Wit, C.; Folke, C.; Gerten, D.; Heinke, J.; Mace, G.; Persson, L.; Ramanathan, V.; Reyers, B.; Sörlin, S. (2015): Planetary boundaries: Guiding human development on a changing planet, Science, 347 (6223), 736-746.

Suh, S. Suh, S., Lenzen, M., Treloar, G., Hondo, H., Horvath, A., Huppens, G., Jolliet, O., Klann, U., Krewitt,W.,Moriguchi, Y., Munksgaard, J., Norris, G.A., 2004. System boundary selection in life-cycle inventories using hybrid approaches, Environmental Science and Technology, 38 (3), 657-664.

Säynäjoki, A., Heinonen J., Junnila, S. (2012): A scenario analysis of the life cycle greenhouse gas emissions of a new residential area, Environmental Research Letters 7 No. 3.

The Building Information Foundation RTS (2010): The Finnish Building Classification System Talo 2000 (Building 2000), available at https://www.rakennustieto.fi/index/english/productsandservices/finnishbuildingclassificationsystem.ht $\mathrm{ml}$ (Accessed on June 30 2015).

The Building Information Foundation RTS (2014): Emission Classification of Building Materials, available at http://m1.rts.fi/en/emission-classification-of-building-materials-836edfcc-8e39-4ec5-abe1ca2d52f78998 (Accessed on June 30 2015). 
Thormark, C. (2002): A low energy building in a life cycle-lts embodied energy, energy need for operation and recycling potential, Building and Environment, 37 (4), 429-435.

Treloar, G. J.; Love, P. E. D.; Faniran, O. O.; Iyer-Raniga, U. (2000): A hybrid life cycle assessment method for construction, Construction Management and Economics 18, 5-9.

UNEP (2009): Buildings and Climate Change, United Nations Environment Programme, Available at www.unep.org/sbci/pdfs/sbci-bccsummary.pdf (Accessed on 4 January 2015).

WWF (2014): Living Planet Report 2014: Species and spaces, people and places, ISBN 978-2-940443-87-1.

Zabalza Bribián I.; Aranda Usón, A.; Scarpellini, S. (2009): Life cycle assessment in buildings: State-of-theart and simplified LCA methodology as a complement for building certification, Building and Environment, 44, 2510-2520.

Zabalza Bribián, I.; Valero Capilla, A.; Aranda Usón, A. (2011): Life cycle assessment of building materials: Comparative analysis of energy and environmental impacts and evaluation of the eco-efficiency improvement potential, Building and Environment, 46 (5), 1133-1140. 